\title{
Uma resenha de $O$ individualismo e os intelectuais
}

\author{
A review of Individualism and the intellectuals
}

Hilton Costa ${ }^{a}$

Durkheim, Émile. O individualismo e os intelectuais. Ed. bilíngüe. Organização e edição: Márcia Consolim, Márcio de Oliveira, Raquel Weiss. São Paulo: Editora da Universidade de São Paulo, 2016.

O Centro Brasileiro de Estudos Durkheiminianos apresenta ao público uma iniciativa bastante ousada e muito significativa para as Ciências Sociais brasileiras: a organização da Biblioteca Durkheiminiana. Abrigada pela Editora da Universidade de São Paulo, a Biblioteca Durkheiminiana contará inicialmente com seis volumes, três deles já lançados. $O$ primeiro a ser publicado foi $O$ individualismo e os intelectuais, de Émile Durkheim; o segundo foi o Estudo sumário da representação do tempo na religião e na magia, de Henri Hubert; o terceiro, Como as palavras mudam de sentido, de Antoine Meillet. Abordar-se-á aqui o primeiro volume.

A Biblioteca Durkheiminiana oferece ao público, além de novas traduções de alguns textos e traduções de textos inéditos, o formato bilíngue, permitindo que se coteje e reflita acerca das opções das tradutoras e dos tradutores. As edições contam com a paginação original presente nos textos em francês, colaborando para a compreensão de como estes artigos circularam pela primeira vez. As informações sobre a trajetória de cada texto são tratadas com atenção: onde foi publicado originalmente em francês (o mesmo para a língua portuguesa), quantas foram as traduções, quem traduziu, onde foi publicado. As opções de tradução e as versões dos originais utilizadas (incluindo onde elas podem ser localizadas) são informações não sonegadas pela equipe que organiza a Biblioteca Durkheiminiana.

Nas palavras da coordenação da coleção, de modo a "fugir do molde de uma tradução pura, a Biblioteca Durkheiminiana propõe ao público brasileiro e internacional edições bilíngues e críticas de textos pouco conhecidos ou já esgotados.” (Benthien; Weiss, 2016, p. 12). Outros pontos marcantes da coleção são as apresentações e os dossiês críticos.

a Professor do Departamento de Ciências Sociais da Universidade Estadual de Maringá (UEM). Graduado em História e Ciências Sociais pela Universidade Federal do Paraná (UFPR), mestre em História pela Universidade Federal do Rio Grande do Sul (UFRGS) e doutor em História pela UFPR. 
No caso do primeiro volume da Biblioteca Durkheiminiana, $O$ individualismo e os intelectuais, a apresentação foi escrita por Márcia Consolim, Márcio de Oliveira e Raquel Weiss, e é muito útil para compreender o contexto de produção da obra, bem como a conjuntura de sua circulação inicial. Desta forma, destacam-se a relação de Durkheim com a Terceira República Francesa - Durkheim figurava entre "os intelectuais e cientistas comprometidos com a consolidação da Terceira República” (Consolim; Oliveira; Weiss, p. 17) - e algumas de suas relações com a Ciência - para ele a Ciência não criaria ideias, todavia demonstraria que todos os ideais são socialmente construídos (Consolim; Oliveira; WeIss, 2016, p. 18).

$\mathrm{O}$ artigo $\mathrm{O}$ individualismo e os intelectuais é também significativo por deixar bastante nítida uma faceta pouco conhecida e/ou pouco divulgada de Émile Durkheim - o seu engajamento público (Consolim; Oliveira; Weiss, 2016, p. 18). "O artigo 'Lindividualisme et les intellectuels' foi originalmente publicado na Revue politique et littéraire, conhecida como Revue bleue." (Consolim; Oliveira; WEISs, 2016, p. 19). A reflexão de Durkheim "veio a público em 2 de julho de 1898 com uma reação ao artigo de Ferdinand Brunetière" (Consolim; Oliveira; Weiss, 2016, p. 19). Eis que se revela o envolvimento do autor no caso Dreyfus, mais precisamente na defesa do capitão. Pois, como tantas outras pessoas envolvidas na polêmica, Durkheim nota como o capitão Dreyfus foi transformado numa espécie de bode expiatório da frustração francesa pós-derrota para a Prússia. $\mathrm{O}$ referido caso mobilizava questões religiosas, animava o antisemitismo, o racismo, a xenofobia da sociedade francesa. E esta situação de caos e ódio era devidamente alimentada pela imprensa (Consolim; Oliveira; Weiss, 2016, p. 26-27). O capitão foi condenado num primeiro momento, o caso a muito custo foi reaberto, e a inocência de Dreyfus foi reconhecida pelo Estado francês somente anos depois da libertação do acusado. A presente edição de $O$ individualismo e os intelectuais traz o artigo de Ferdinand Brunetière, Após o processo (p. 135-167), que motivou o texto de Durkheim, entre os anexos.

\section{O INDIVIDUALISMO E OS INTELECTUAIS}

Émile Durkheim abre sua discussão sobre o individualismo e os intelectuais localizando o debate do qual seu texto faz parte - o caso Dreyfus - e em seguida dá início à exposição sobre a forma como entende o individualismo. Afirma ele que "Antes de qualquer coisa, é preciso desfazer-se de um primeiro equívoco." (DurkHEIM, 2016, p. 41). O equívoco em questão seria uma apreensão unidimensional do individualismo - este se apresentaria sob vários contornos. Durkheim caminha, então, na direção de indicar o individualismo sob perspectivas múltiplas. Ele critica o 
individualismo quando confundido com o utilitarismo. Para Durkheim, confundir o individualismo com o utilitarismo seria uma arma dos adversários do primeiro. "Para criticar mais facilmente o individualismo, confundem-no com utilitarismo estreito e com o egoísmo utilitário de Spencer e dos economistas." (DURKHEIM, 2016, p. 41). Também se faz presente a crítica ao individualismo abstrato atribuído aos "espiritualistas"; esta interpretação do individualismo, para Durkheim, seria a mais difícil de ser "vencida" (Durkheim, 2016, p. 43).

A crítica às interpretações hegemônicas do individualismo de sua época é, em grande medida, acompanhada da "defesa" de uma espécie particular de individualismo que não seja algum tipo de culto ao eu. De modo a ser viável inferir que a ideia de indivíduo não deveria ser tratada a partir e/ou tomando as características de uma pessoa em particular (DurкhEIM, 2016, p. 49). Outro aspecto da discussão acerca da individualidade passível de ser retomado neste texto é a ideia do indivíduo e da individualidade como produtos do coletivo. Assim, estas categorias só poderiam existir em ambientes onde a coletividade zelasse pela manutenção das mesmas - um valor majoritário do conjunto de uma sociedade dada. O individualismo nesta chave não deriva "necessariamente de sentimentos individuais", mas sim de "uma instituição social” (DurkhEIM, 2016, p. 61).

$\mathrm{O}$ individualismo interpretado desta forma cria um entendimento e/ou uma percepção da liberdade individual como uma premissa básica de uma sociedade dada. Assim, as liberdades individuais não deveriam ser suprimidas e/ou deixadas à margem em função de uma razão de Estado. Os direitos das pessoas estariam acima dos direitos do Estado. A defesa dos direitos individuais seria a razão do Estado. Desta forma, o julgamento justo, o direito à ampla defesa, para se deter no caso que deu origem ao artigo, seria a razão do Estado. Do Estado formado a partir de um corpo social onde o indivíduo e o individual são premissas fundamentais, ou seja, de uma coletividade que tem essas categorias como base de sua organização.

A situação inversa - os direitos do Estado acima dos direitos das pessoas como base de uma organização social pode se revelar, por exemplo, através da adesão instrumental ao individualismo. Durkheim demonstra que o individualismo construído sobre o alicerce do utilitarismo produz a adesão instrumental ao individualismo. "A doutrina utilitarista pode facilmente aceitar todo o tipo de compromisso, sem falsear seu axioma fundamental, assim como pode admitir que as liberdades individuais sejam suspensas todas as vezes que o interesse da maioria exija tal sacrifício.” (Durkheım, 2016, p. 45). Acerca desta situação, Durkheim asseverou: "não se pode aceitar um princípio situado fora e acima de todos os interesses temporais. Não há razão de Estado que possa desculpar um 
atentado contra a pessoa quando os direitos da pessoa estão acima do Estado.” (Durkheim, 2016, p. 45).

Entre as liberdades individuais estaria a liberdade de opinião e/ou direito à opinião. $\mathrm{O}$ individualismo, nesta chave interpretativa - a preservação das liberdades individuais -, seria o lugar pelo qual os e as intelectuais poderiam se manifestar publicamente. Com efeito, os intelectuais não interfeririam nas questões públicas - como discordar de um julgamento que eles considerassem suspeito - por serem tipos especiais de pessoas, mas sim por serem indivíduos, que teriam, como as demais pessoas, o direito de manifestar sua opinião. A opinião das intelectuais e dos intelectuais apresentaria algumas particularidades formadas em função de seus hábitos de trabalho como, por exemplo, se dobrar facilmente "aos impulsos da multidão" (Durkheim, 2016, p. 53). Todavia, a característica particular não faria da figura do intelectual um ser "especial", pois toda opinião possuiria aspectos particulares.

\section{SOBRE 0 INDIVIDUALISMO E OS INTELECTUAIS}

O dossiê crítico, elemento bastante interessante dos volumes da Biblioteca Durkheiminiana, conta neste primeiro título com artigos de Louis Pinto, "Durkheim, o intelectual como mandatário do universal"; Márcia Consolim, "O século das 'Grandes Revistas' Parisienses: A Revue des deux mondes e a Revue bleue antes do Affaire"; Susan Stedman Jones, "O individualismo"; Raquel Weiss, "Durkheim, um 'intelectual' em defesa do 'ideal humano”; William Watts Miller, "O individualismo e os intelectuais de Durkheim". Completa o dossiê crítico uma biobliografia de Émile Durkheim.

Tomando os artigos do dossiê crítico em conjunto, eles permitem à leitora e ao leitor pensar em termos de outros Durkheim. Argumenta-se que a interpretação típica da obra durkheiminiana no Brasil foi muito marcada pela leitura parsoniana (Talcott Parsons, 1902-1979). Esta situação teria obliterado outras características do pensamento e da teoria do autor, das quais muito possivelmente as questões do indivíduo e do individual sejam um dos esquecimentos mais significativos. Pois durante largo período de tempo afirmou-se que Durkheim e sua teoria não abriam espaço ao indivíduo e ao individual, o que não necessariamente corresponde ao que está presente nos seus escritos. Émile Durkheim não seria simpático ao individualismo metodológico - isto é diferente da negação do indivíduo e do individual. A concepção do indivíduo e do individual como produtos coletivos, instituições sociais, também pode ter contribuído para a interpretação que via Durkheim como um opositor do individualismo. O dossiê crítico enfatiza ainda 
como Durkheim se colocava diante da ação pública dos e das intelectuais, bem como das e dos cientistas. Fato conhecido, em grande medida, somente nos círculos dedicados ao estudo sistemático da obra durkheiminiana. E que esta coleção traz a um público maior.

É recorrente a quem leciona para os anos iniciais dos cursos da área de Humanidades, notadamente nos de Ciências Sociais, ouvir a seguinte indagação, vinda das e dos discentes: por que ler os clássicos? De fato, esta questão possui muitas respostas possíveis, que certamente fogem ao escopo desta resenha. Entretanto, a leitura de $O$ individualismo e os intelectuais pode ser um dos caminhos para responder à dita questão. A obra, à qual se somam a apresentação e o dossiê crítico, permite localizar aquilo que para vários autores e autoras caracteriza um “clássico": ferramentas interpretativas e analíticas que seguem úteis e pertinentes.

\section{REFERÊNCIAS BIBLIOGRÁFICAS}

Benthien, Rafael Faraco; Weiss, Raquel. "Nota dos coordenadores da coleção”. In: Durkheim, Émile. O individualismo e os intelectuais. Ed. bilíngüe. Organização e edição: Márcia Consolim, Márcio de Oliveira, Raquel Weiss. São Paulo: Editora da Universidade de São Paulo, 2016.

Consolim, Márcia; Oliveira, Márcio de; Weiss, Raquel. “Apresentação do volume”. In: Durкheim, Émile. O individualismo e os intelectuais. Ed. bilíngüe. Organização e edição: Márcia Consolim, Márcio de Oliveira, Raquel Weiss. São Paulo: Editora da Universidade de São Paulo, 2016.

Consolim, Márcia. “O século das 'Grandes Revistas' Parisienses: A Revue des deux mondes e a Revue bleue antes do Affaire”. In: Durкherm, Émile. O individualismo e os intelectuais. Ed. bilíngüe. Organização e edição: Márcia Consolim, Márcio de Oliveira, Raquel Weiss. São Paulo: Editora da Universidade de São Paulo, 2016.

Durкheıм, Émile. O individualismo e os intelectuais. Ed. bilíngüe. Organização e edição: Márcia Consolim, Márcio de Oliveira, Raquel Weiss. São Paulo: Editora da Universidade de São Paulo, 2016.

HUbERT, Henri. Estudo sumário da representação do tempo na religião e na magia. Ed. bilíngüe. Organização e edição: Rafael Faraco Benthien, Miguel Soares Palmeira, Rodrigo Turin. São Paulo: Editora da Universidade de São Paulo, 2016.

Jones, Susan Stedman. "O individualismo”. In: Durkheim, Émile. O individualismo e os intelectuais. Ed. bilíngüe. Organização e edição: Márcia Consolim, Márcio de Oliveira, Raquel Weiss. São Paulo: Editora da Universidade de São Paulo, 2016. 
Meillet, Antoine. Como as palavras mudam de sentido. Ed. bilíngüe. Organização e edição: Rafael Faraco Benthien, Miguel Soares Palmeira. São Paulo: Editora da Universidade de São Paulo, 2016.

Miller, William Watts. "O individualismo e os intelectuais de Durkheim”. In: Durkheim, Émile. O individualismo e os intelectuais. Ed. bilíngüe. Organização e edição: Márcia Consolim, Márcio de Oliveira, Raquel Weiss. São Paulo: Editora da Universidade de São Paulo, 2016.

Pinto, Louis. "Durkheim, o intelectual como mandatário do universal”. In: Durkheim, Émile. O individualismo e os intelectuais. Ed. bilíngüe. Organização e edição: Márcia Consolim, Márcio de Oliveira, Raquel Weiss. São Paulo: Editora da Universidade de São Paulo, 2016.

WeIss, Raquel. "Durkheim, um 'intelectual' em defesa do 'ideal humano”. In: Durkheim, Émile. O individualismo e os intelectuais. Ed. bilíngüe. Organização e edição: Márcia Consolim, Márcio de Oliveira, Raquel Weiss. São Paulo: Editora da Universidade de São Paulo, 2016. 